\title{
PELATIHAN TEKNIK PEWARNAAN BAGI PENGRAJIN TENUN DESA NEKMESE KECAMATAN AMARASI SELATAN
}

\author{
Rima Nindia Selan'1), Ariency K. Ada Kale'1), Theodora M. Tualaka1) \\ 1)Program Studi Teknik Pembuatan Tenun Ikat, Fakultas Sains dan Teknik, Universitas Nusa Cendana, Kupang, NTT \\ Corresponding author : Rima Nindia Selan \\ E-mail : rima_selan@staf.undana.ac.id
}

Diterima 12 Juli 2021, Direvisi 06 Agustus 2021, Disetujui 06 Agustus 2021

\begin{abstract}
ABSTRAK
Kegiatan pengabdian kepada masyarakat ini bertujuan memperkenalkan dan melatih para pengrajin untuk menggunakan teknik pewarnaan celup dengan zat warna napthol, yang dapat menjaga warna tetap awet dan kualitas hasil tenun lebih baik. Kain Tenun NTT memiliki banyak motif yang sangat menarik dan sudah terkenal tidak hanya di Indonesia tetapi juga di Luar Negeri. Untuk mempertahankan kualitas kain tenun, maka pengrajin harus memperhatikan teknik pewarnaan. Selama ini pengrajin tenun Desa Nekmese menggunakan wantex sebagai bahan untuk pewarna, tetapi kelemahannya warna kain tenun akan luntur jika dicuci. Dengan kegiatan pengabdian ini pengrajin mendapat tambahan pengetahuan teknik pewarnaan dengan menggunakan zat warna napthol yang dapat menjaga kualitas warna kain tenun. Kegiatan pengabdian ini dilakukan dengan menggunakan pendekatan pelatihan dan praktek langsung, sehingga peserta bisa memahami setiap prosesnya serta hasil pengabdian peserta sudah mampu mengalikasikan teknik pewarnaan celup dengan zat warna napthol.
\end{abstract}

Kata kunci: teknik pewarnaan; pengrajin tenun; zat warna napthol.

\begin{abstract}
This Community Service activity aims to introduce and train craftsmen to use the dyeing technique with naphthol dyes, which can keep the color durable and the quality of the weaving better. NTT Woven Fabrics have many very interesting motifs and are well known not only in Indonesia but also abroad. To maintain the quality of woven fabrics, craftsmen must pay attention to coloring techniques. So far, the weaving craftsmen of Nekmese Village use wantex as a dye, but the weakness is that the color of the woven fabric will fade when washed. With this service activity, craftsmen get additional knowledge of coloring techniques using naphthol dyes that can maintain the color quality of woven fabrics. This service activity is carried out using a training approach and direct practice so that participants can understand each process and the results of the service participants can apply dyeing techniques with naphthol dyes.
\end{abstract}

Keywords: coloring technique; weavers; naphthol dye.

\section{PENDAHULUAN}

Di masyarakat NTT, motif tenun dapat mencirikan dari mana pemakai berasal. Sebabdalam motif kain tenun tergambar cirik has suatu suku atau pulau. Setiap daerah memiliki motif dan warnadasar yang berbeda beda, begitu juga halnya dengan tenunan dari Kecamatan Amarasi Selatan, Kabupaten Kupang. Kecamatan Amarasi Selatan berada di Kawasan Kabupaten Kupang dengan luas wilayah $172,81 \mathrm{Km}^{2}$ dan jumlah penduduk 9.542 jiwa merupakan daerah tujuan wisata karena terdapat Pantai BatuTujuh dan Pantai Teres yang menjadi kebanggan Kabupaten Kupang (Kecamatan-Amarasi-Selatan-DalamAngka-2019, n.d.). Karena berada di dataran Timor kain adat KecamatanAmarasi Selatan banyak mengikuti suku Timor, yaitu memiliki warna dasar terang (seperti warna merah dan orange)(Utami, 2018).

Semenjak kepemimpinan Gubernur Viktor Laiskodat, kain tenun NTT diangkat menjadi busana wajib bagi pegawai negeri setiap hari Kamis dan Jumat. Hal ini untuk mendorong para pengrajin tenun agar terus mengembangkan usahanya serta mempertahankan dan memajukan kearifan lokal.

Selain digunakan di lingkungan lokal, tenunan NTT juga sudah terkenal di kancah internasional. September 2017 untuk pertama kalinya tenunan asal NTT tampil dalam pergelaran tunggal Couture New York Fashion Week. Selanjutnya 27 Februari sampai dengan 6 Maret 2018, Ibu Gubernur NTT membawa kain tenun NTT keajang pergelaran mode bergengsi di dunia, yakni Paris Fashion Week 
2018(Strategi Pengembangan Tenun Ikat Kupang Provinsi Nusa Tenggara Timur, n.d.). $\mathrm{Hal}$ inilah yang mendasari pentingnya pemberdayaan kelompok pengrajin tenun lewat KelompokT enun Desa Nekmese di Kecamatan Amarasi Selatan.

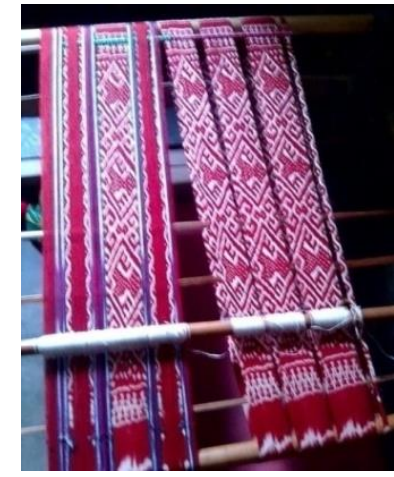

Gambar 1. TenunanAmarasi

Beberapa kendala yang dihadapi para pengrajin antara lain kurangnya pengetahuan tentang teknik pewarnaan sehingga tidak ada variasi warna hasil tenunan. Pelatihan Pewarnaan dan Inovasi Tenun lkat untuk mengatasi permasalahan pewarnaan yang lama. Dalam pelatihan ini akan diperkenalkan penggunaan pewarna tekstil sebagai pelengkap, peningkat varian warna selain pewarna alami. Pewarn atekstil ini juga akan membantu menyediakan varian warna dengan waktu yang lebih cepat dalam pewarnaan(Pewarna Sintetis, n.d.).

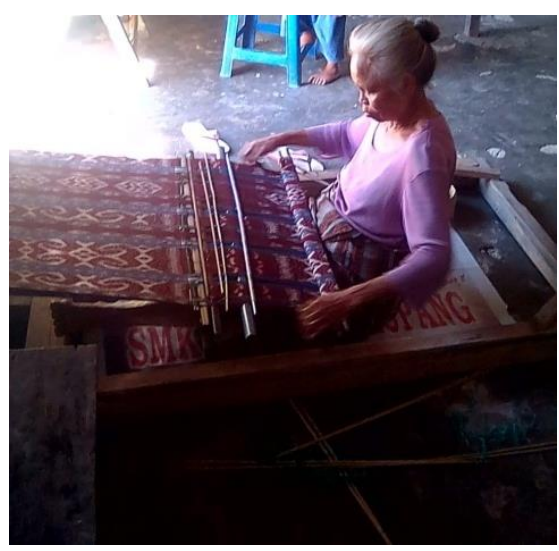

Gambar 2. AlatTenunTradisional

Selama ini hanya ibu - ibu yang terampil menenun, sedangkan kaum muda kurang tertarik belajar menenun. Oleh karena itu, dengan program ini dapat menjaring kaum muda untuk tertarik meneruskan budaya menenun dan mengembangkannya.

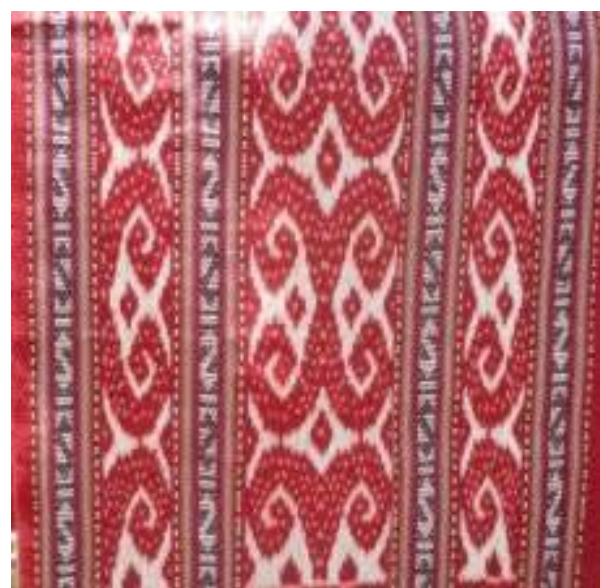

Gambar 3. Kain TenunAmarasi

Untuk menghasilkan 1 sarung (2 lembar tenunan ukuran 1 meter $\times 2$ meter), pengrajin tenun Kecamatan Amarasi Selatan membutuhkan waktu 1 bulan. Harga 1 buah sarung tenun di pasar local berkisar antara $\mathrm{Rp}$. 2.000.000,-sampaiRp. 2.500.000,- . Belum ada perhitungan yang pasti biaya bahan baku yang digunakan untuk menghasilkan 1 buah sarung, sehingga besarnya keuntungan yang didapat tidak bisa di pastikan. Untuk sarung yang terjual dalam jangka waktu 1 bulan juga tidak tentu, kalua kunjungan wisatawan ke Pantai Teres ramai bisa terjual 5-10 lembar sarung.

Sebagai bentuk jawaban dari permasalahan tersebut, tim pelaksana melaksanakan kegiatan pelatihan teknik pewarnaan menggunakan cairan napthol bagi pengrajin tenun di Kelompok Tenun Desa Nekmese, pemberian pelatihan teknik pewarnaan bertujuan meningkatkan pengetahuan tentang pewarnaan buatan dalam proses menenun tetapi tetap menjaga mutu dan kulitas hasil tenunan. Tim pelaksana akan mendampingi sampai mitradapat mandiri.

\section{METODE}

Pelaksanaan kegiatan pengabdian kepada masyarakat dilakukan dalam tiga tahapan penting yaitu survey dan pengumpulan data untuk mengetahui masalah yang dihadapi mitra, tahap kedua yaitu pelatihan teknik pewarnaan, serta tahap ketiga yaitu ealuasi dan monitoring untuk mengetahui sejauh mana mitra dapat mengaplikasikan ilmu pengetahuan yang sudah ditransfer atau dibagikan.

Kegiatan pengabdian kepada masyarakat dilakukan pada hari Sabtu, tanggal 3 Juli 2021 bertempat di Dusun 1 Desa Nekmese, Kecamatan Amarasi Selatan, Kabupaten Kupang.

Mitra dari kegiatan pengabdian masyarakat kali ini merupakan kelompok tenun ikat Desa Nekmese yang di ketuai oleh Ibu Emy Doko 
dan terdiri dari 15 orang anggota. Kelompok tenun ikat ini sudah berdiri dari tahun 2014. Tetapi baru kali ini mitra mendapat tambahan penetahuan tentang teknik pewarnaan dengan zat warna napthol.

Tahapan-tahapan yang ditempuh guna melaksanakan solusi atas permasalahan mitra, antara lain (Cara Celup Warna Napthol, n.d.):

1. Menggali dan mengkaji permasalahan yang dihadapi mitra melalui wawancara/dialog yang mendalam tentang potensi dan kendala/permasalahan yang dihadapi mitra Kelompok Tenun Ikat Desa Nekmese.

2. Menetapkan solusi yang sesuai dengan persoalan yang dihadapi mitra dan mengumpulkan data-data awal sebagai landasan dalam menawarkan solusi kepada mitra.

3. Menawarkan solusi kepada mitra berupa kegiatan pelatihan tentang teknik pewarnaan dari pakar untuk meningkatkan pemahaman mitra.

4. Melakukan kesepakatan bersama dalam hal teknis penyelesaian persoalan mitra.

5. Penyediaan alat dan bahan untuk kegiatan PKM.

6. Melakukan pendampingan dan pengawasan setelah program selesai sampai mitra mandiri dalam memanfaatkan ipteks yang diberikan.

Langkah - langkah proses pewarnaan adalah sebagai berikut :

1. Mencuci benang yang akan digunakan

2. Celupkan di larutan pertama (Napthol, cosic soda, TRO garam dapur dan air panas) secara cepat.

3. Celupkan di larutan kedua (untuk tiap warna berbeda - beda). Larutan kedua menggunakan air dingin.

4. Benang yang sudah berwarna kemudian dicuci dengan air sabun.

5. Langkah terakhir adalah menjemur benang hingga kering.

\section{HASIL DAN PEMBAHASAN}

Hasil

Urutan pelaksanaan kegiatan Pengabdian Kepada Masyarakat (PKM) Kelompok Tenun Desa Nekmese Kecamatan Amarasi Selatan, dapat dilihat pada gambar dibawah ini:

1. Narasumber memberikan materi tentang penggunaan zat pewarna napthol dalam proses pewarnaan benang tenun.

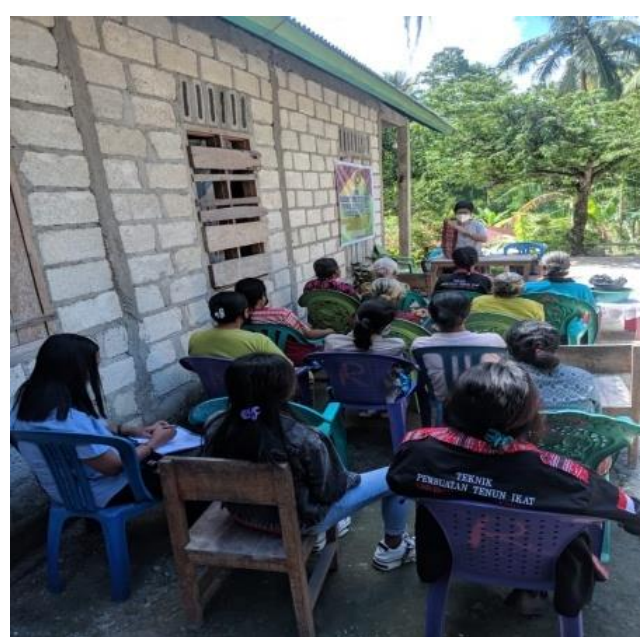

Gambar 4. Narasumber Memberi Materi Pelatihan

2. Selanjutnya peserta langsung mempraktikkan sesuai arahan dari narasumber. Proses pertama yaitu proses pelurusan benang sehingga pada saat pencucian tidak ada benang yang kusut.

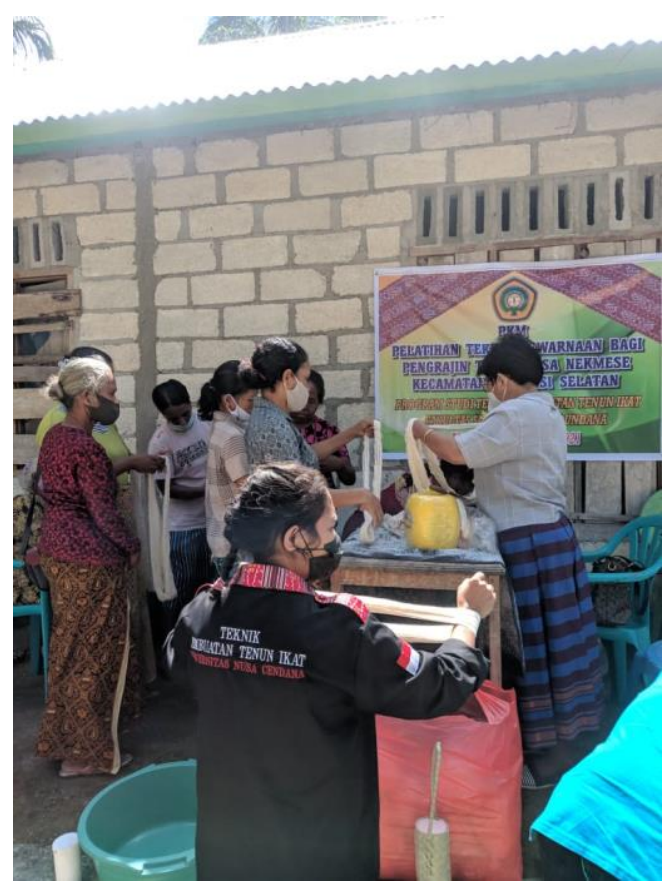

Gambar 5. Proses Pelurusan Benang

3. Proses berikut adalah pencucian benang dengan air dingin, hal ini dimaksudkan agar benang bersih dan dapat menyerap warna pada saat pencelupan dengan zat warna napthol. 


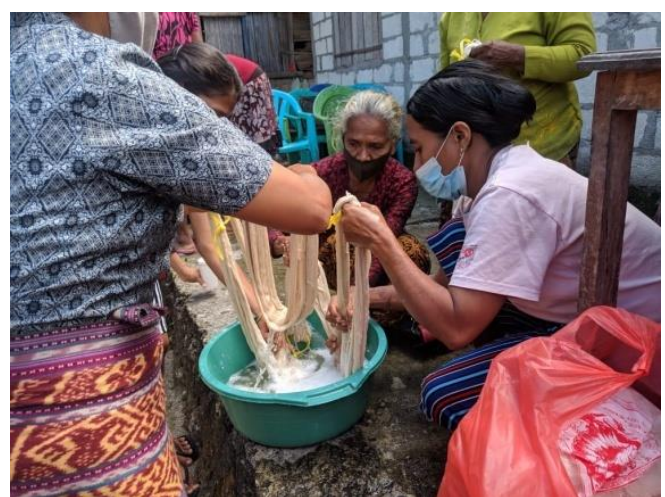

Gambar 6. Proses Pencucian Benang Sebelum Dicelupkan

4. Setelah benang dicuci, maka dilanjutkan dengan proses pencelupan dengan zat warna napthol. Zat warna yang digunakan disesuaikan dengan kebutuhan warna tenunan.

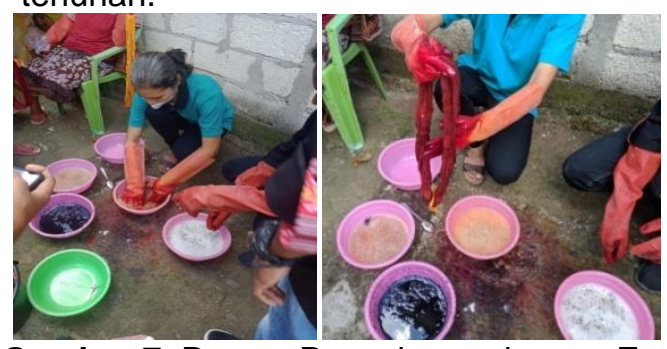

Gambar 7. Proses Pencelupan dengan Zat Warna Napthol

5. Proses selanjutnya yaitu proses pencucian akhir menggunakan sabun cuci untuk menghilangkan sisa - sisa zat warna napthol.

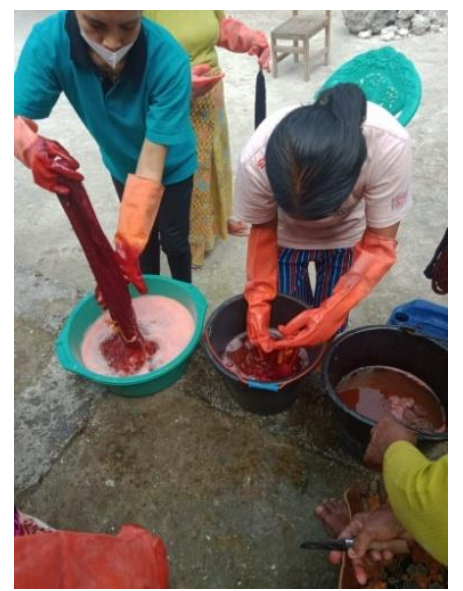

Gambar 8. Proses Pencucian Akhir

6. Proses terakhir yaitu penjemuran benang yang sudah diwarnai, setelah kering maka benang sudah dapat digunakan untuk proses menenun.

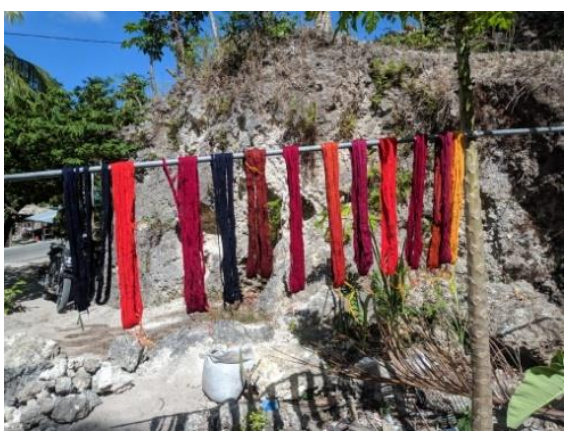

Gambar 9. Proses Penjemuran Benang

Hasil dari kegiatan Pengabdian Kepada Masyarakat (PKM) Kelompok Tenun Desa Nekmese Kecamatan Amarasi Selatan, yaitu :

- Pelatihan teknik pewarnaan menggunakan zata warna Napthol. Kegiatan dilakukan Bulan Juli bertempat di Kelompok Tenun Desa Nekmese, Kecamatan Amarasi Selatan. Penyuluhan diikuti oleh 10 orang pengrajin anggota Kelompok Tenun Desa Nekmese. Peserta sangat antusias dan banyak memberikan pertanyaan pada sesi tanya jawab, karena mendapat pengetahuan baru tentang pewarnaan. Selama ini pengarajin menggunakan wantex sehingga mengurangi kualitas tenun yang dihasilkan. Dengan pelatihan ini, peserta yang merupakan pengrajin tenun mendapat peningkatan ilmu pengetahuan tentang teknik pewarnaan menggunakan zat warna napthol yang lebih baik daripada yang selama ini digunakan.

- Narasumber yang merupakan ketua Sentra Tenun INA NDAO menawarkan kerjasama untuk promosi dan penjualan hasil tenun dari pengrajin tenun Desa Nekmese, sehingga penjualan tidak hanya mencakup pasar lokal tetapi juga hasil tenunan bisa dipasarkan lebih luas.

\section{Pembahasan}

Berdasarkan hasil kegiatan PKM menyatakan bahwa pengrajin di Kelompok Tenun Desa Nekmese sudah menenun selama puluhan tahun, tetapi belum mempunyai pengetahuan tentang teknik pewarnaan buatan yang berkualitas. Selama ini, pengrajin menggunakan pewarnaan alami yang memakan waktu lama dan bila dijual harganya mahal. Untuk pewarnaan buatan pengrajin menggunakan bahan wantex yang bila dicuci maka hasil tenunan akan luntur dan mengecewakan pembeli.

Kegiatan PKM membawa dampak positif bagi pengrajin karena mereka dapat memahami tentang teknik pewarnaan buatan dengan zat warna napthol, dimana penggunaan zat warna ini dapat menjaga mutu dan kualitas hasil 
tenunan. Zat warna napthol atau azoic adalah zat warna yang warnanya terbentuk didalam serat waktu pencelupan yang merupakan hasil reaksi komponen senyawa napthol dengan senyawa garam diaanzonium.

Selain itu, lewat kegiatan pengabdian ini Narasumber lbu Dorce Lussi yang merupakan pemilik Sentra Tenun Ina Ndao menawarkan kerjasama kepada Kelompok Tenun Desa Nekmese untuk membantu proses pemasaran dan penjualan produk hasil tenunan dari Kelompok Tenun Desa Nekmese.

Monitoring dan Evaluasi dilakukan secara online karena masih dalam kondisi PPKM, mitra sudah menerapkan teknik pewarnaan sesuai yang diajarkan, serta sudah mulai melakukan proses menenun. Hal yang menjadi kendala yaitu bahan baku yang susah didapat, karena harus dibeli di Kota Kupang. Di Desa Nekmese beum tersedia toko yang menjual bahan pewarna napthol untuk tenunan.

\section{SIMPULAN DAN SARAN}

Peserta kegiatan yang merupakan pengrajin tenun Desa Nekmese sangat antusias dalam mengikuti kegiatan PKM pelatihan teknik pewarnaan ini. Setelah narasumber memberikan materi, maka peserta langsung memraktikkan sendiri, para peserta dengan cepat memahami dan dapat melakukan teknik pewarnaan dengan proses pencelupan zat warna napthol sesuai arahan dari narasumber.

Dengan ilmu pengetahuan yang didapat lewat kegiatan PKM ini diharapkan untuk tahap selanjutnya mitra dapat mengembangkan usaha tenunan dan menghasilkan tenunan dengan kualitas yang lebih baik.

\section{UCAPAN TERIMAKASIH}

Ucapan terima kasih disampaikan kepada dan Fakultas Sains dan Teknik Universitas Nusa Cendana untuk pembiayaan pengabdian ini, melalui DIPA Universitas nusa Cendana TA 2021 dengan Perjanjian Kontrak No.70/UN15.15.2.PPK/SPP/FST/IV/2021.

Tim PKM juga mengucapkan terima kasih kepada Kelompok Tenun Ikat Dusun 1 Desa Nekmese serta semua anggota yang telah menjadi mitra untuk kegitan ini.

Tim PKM mengucapkan terima kasih juga kepada Sentra Tenun Ina Ndao selaku narasumber yang telah membagikan ilmu yang sangat berguna bagi mitra.

\section{DAFTAR RUJUKAN}

Cara celup warna Napthol. (n.d.). https://youtu.be/JmsliC9SPFg

Kecamatan-amarasi-selatan-dalam-angka2019.

(n.d.).
Volume 5, Nomor 1, Desember 2021.

p-ISSN : 2614-5251

e-ISSN : 2614-526X

3.https://kupangkab.bps.go.id/publicati on/2019/09/26/5620e2d743ae583cd08 $1 \mathrm{dfdc} /$ kecamatan-amarasi-selatandalam-angka-2019.html

Pewarna sintetis. (n.d.). 4.https://fitinline.com/ article/read/pewarna-sintetis/

Strategi Pengembangan Tenun Ikat Kupang Provinsi Nusa Tenggara Timur. (n.d.). 2.http://www.researchgate.net/publicati on/323635721_Strategi_Pengembang an_Tenun_lkat_Kupang_Provinsi_Nus a_Tenggara_Timur

Utami, A. N. (2018). Tenun Ikat Amarasi Kabupaten Kupang Nusa Tenggara Timur. 07, 1-6. 